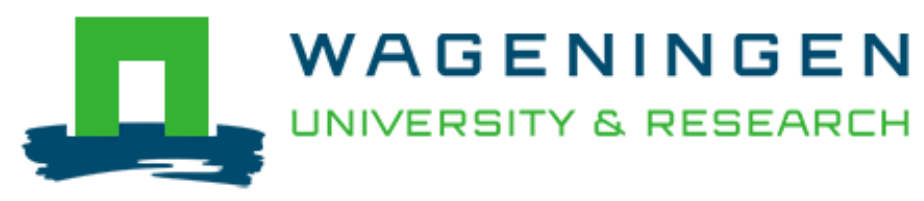

Simulations of osmotic events in vitrification of equine oocytes and porcine embryos

Woelders, H., Guignot, F., Oritiz-Escribano, N., van Soom, A., \& Smits, K.

This is a "Post-Print" accepted manuscript, which has been Published in "Cryobiology"

This version is distributed under a non-commercial no derivatives Creative Commons (c) (1) (9) (CC-BY-NC-ND) user license, which permits use, distribution, and reproduction in any medium, provided the original work is properly cited and not used for commercial purposes. Further, the restriction applies that if you remix, transform, or build upon the material, you may not distribute the modified material.

Please cite this publication as follows:

Woelders, H., Guignot, F., Oritiz-Escribano, N., van Soom, A., \& Smits, K. (2018). Simulations of osmotic events in vitrification of equine oocytes and porcine embryos. Cryobiology, 85, 154-155. https://doi.org/10.1016/j.cryobiol.2018.10.136

You can download the published version at:

https://doi.org/10.1016/j.cryobiol.2018.10.136 


\title{
SIMULATIONS OF OSMOTIC EVENTS IN VITRIFICATION OF EQUINE OOCYTES AND PORCINE EMBRYOS
}

\author{
Henri Woelders ${ }^{1 *}$, Florence Guignot ${ }^{2}$, Nerea Ortiz-Escribano ${ }^{3}$, Ann van Soom ${ }^{3}$, Katrien \\ Smits $^{3}$ \\ ${ }^{1}$ Wageningen UR Livestock Research, Wageningen, the Netherlands; ${ }^{2}$ PRC, Institut National \\ de la Recherche Agronomique (INRA), Tours, France; ${ }^{3}$ Faculty of Veterinary Medicine, \\ Ghent University, Merelbeke, Belgium. Corresponding Author*: henri.woelders@wur.nl
}

High concentrations of cryoprotective agents (CPAs) used for vitrification of equine oocytes and porcine embryos are believed to negatively affect developmental competence. Here, osmotic events were simulated using $2 \mathrm{P}$ formalism (Kleinhans, Cryobiology 37, 271-289) to predict effects of reduced duration of CPA exposure and effects of use of non-permeating CPAs. Varying concentrations of permeating CPAs (ethane-1,2-diol and $\mathrm{Me}_{2} \mathrm{SO}$ ) were used in the first step (equilibration solution, ES) and second step (vitrification solution, VS). In VS, varying concentrations of additional non-permeating solute (sucrose) were used. The duration of the first step (ES) was varied between 0.5-10 min, while exposure to VS was 0.51 min. Values for Lp and Ps were based on published values for oocytes and embryos respectively.

Typical 'volume excursions' are seen, in which oocytes and embryos rapidly ( $<0.5 \mathrm{~min})$ shrink in ES due to efflux of water, then start re-swelling due to combined influx of CPA and water. After transfer to VS, the oocytes/embryos shrink a second time, concentrating intracellular solutes including CPA taken up in step 1. In line with that, the simulations show that the allegedly advantageous reduction of the intracellular concentration of permeating CPAs by non-permeating sucrose is only very small. Further, although with a short $(0.5 \mathrm{~min})$ step 1 (ES), much less permeating CPA is taken up, yet osmolality equal to that of VS $\approx \approx$ 'vitrifiability') is reached in the intracellular- and blastocoel space within seconds after transfer to VS, regardless of step 1 duration. But with a short step 1, the cells will be vitrified while being severely shrunken. These simulations (and indeed experimental evidence we obtained in equine oocytes) suggest there may be an optimum balance of the risk of damage due to long exposure to VS and the (assumed) risk of vitrification of embryos in severely shrunken, condensed condition.

Source of Funding: Contributions by HW and FG were part of the IMAGE project which received funding from the European Union's Horizon 2020 Research and Innovation Programme under the grant agreement $n^{\circ} 677353$.

Conflict of Interest: None to disclose 